\title{
Atypical Extraction of Maxillary Central Incisor for the Correction of Angle Class II Malocclusion
}

\author{
Extracción Atípica de Incisivo Central Maxilar en la \\ Corrección de la Maloclusión de Angle Clase II
}

\begin{abstract}
Anderson Paulo Barbosa Lima1; Graziela Oro Cericato²; Matheus Melo Pithon ${ }^{3}$; Ademir Franco ${ }^{4}$; Alex Moreira Herval ${ }^{5}$ \& Luiz Renato Paranhos ${ }^{5}$
\end{abstract}

LIMA, A. P. B.; CERICATO, G. O.; PITHON, M. M.; FRANCO, A.; HERVAL, A. M. \& PARANHOS, L. R. Atypical extraction of maxillary central incisor for the correction of Angle Class II malocclusion. Int. J. Odontostomat., 13(3):292-298, 2019.

ABSTRACT: This case describes the treatment of Class II malocclusion in a patient missing one of the maxillary central incisors due to traumatic impaction. The treatment approach consisted in the extraction of the remaining maxillary central incisor, followed by diastema closure and re-anatomization of lateral incisors into central incisors. The results obtained were considered satisfactory concerning occlusal, aesthetic and functional aspects. This therapeutic approach may be used as an alternative for similar cases.

KEY WORDS: tooth movement, tooth extraction, Angle class II malocclusion, corrective orthodontics.

\section{INTRODUCTION}

Dental Class II malocclusion is one of the most prevalent orthodontic problems. This type of malocclusion may present different clinical features, such as protruded upper teeth, retruded lower teeth, or even a combination of both (Saikoski et al., 2014; Nagayama et al., 2015).

Several therapeutic approaches may be used to treat this type of malocclusion, among which are distalization of teeth with intra- and extraoral appliances and dental extractions (Hematpour et al. 2014; El Refaei et al., 2014; Pithon, 2014). In the latter, the teeth most commonly selected are premolars. The selection of premolars is based on the middle position of such teeth in the dental arch and their size, as well as the existence of two premolars bilaterally in the hemiarches. However, there are given clinical situations in which the extraction of premolars is not possible; in these cases, other teeth such as molars, incisors, and canines might be involved (Livas et al., 2011; Verma et al., 2013).

When maxillary central incisors are compromised by extensive decay (beyond the cementoenamel junction), fracture, ankylosis, or inappropriate position, their atypical extraction is considered an acceptable alternative (Janson et al., 2010). In this case, several factors should be considered, such as: facial biotype, tooth size and shape, type of occlusion, gap to be closed and root length (Sabri, 2002).

Based on the exposed, this study aims to report the treatment of Class II malocclusion in a patient missing the maxillary central incisor by extracting the contralateral central incisor. The results achieved showed correction of malocclusion with aesthetic and functional gains.

\footnotetext{
${ }^{1}$ Private Practice, São Lourenço, MG, Brazil.

2 Dental School, Faculdade Meridional - IMED, Passo Fundo, RS, Brazil.

${ }^{3}$ Dental School, Universidade Estadual do Sudoeste da Bahia - UESB, Jequié, BA, Brazil.

${ }^{4}$ Department of Therapeutic Stomatology, Institute of Dentistry, I.M. Sechenov First Moscow State Medical University, Moscow, Russian Federation.

${ }^{5}$ Departament of Preventive and Social Dentistry, School of Dentistry, Federal University of Uberlândia, Minas Gerais, Brazil.
} 


\section{CASE REPORT}

An Afro-Caucasian female aged 19.3 years old was referred to the orthodontic clinic complaining of "crooked teeth". The patient was in good general and oral health and presented history of caries and satisfactorily dental restorations. Clinically, the feature that most stood out was the absence of her maxillary left central incisor (tooth \#21).

According to the extra-oral examination and measurements in the lateral teleradiography, the patient had brachyfacial features (SN.GoGn of $23.2^{\circ}, \mathrm{SN} . \mathrm{Gn}$ of $62.3^{\circ}$, and FMA of $21.8^{\circ}$ ), with mild facial asymmetry, convex profile - maxillary protrusion (SNA $95.1^{\circ}$ ) -, and light mandibular retrusion, as shown in Figure 1 and Table I.

The intraoral examination revealed the presence of lower anterior crowding with cast discrepancy of $-3.5 \mathrm{~mm}$, presence of maxillary anterior diastema, absence of the left maxillary central incisor (\#21), and presence of Class II, Division 1 malocclusion with $3 / 4$-complete severity $(7 \mathrm{~mm})$, as shown in Figures 2 and 3.
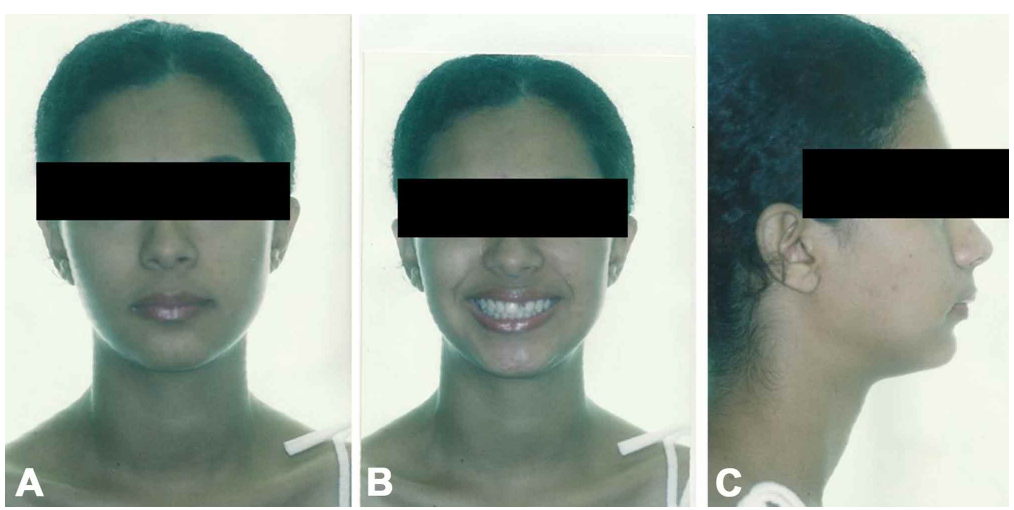

Fig. 1. Extraoral photographs before treatment. A) Front; B) Smiling; C) Profile.
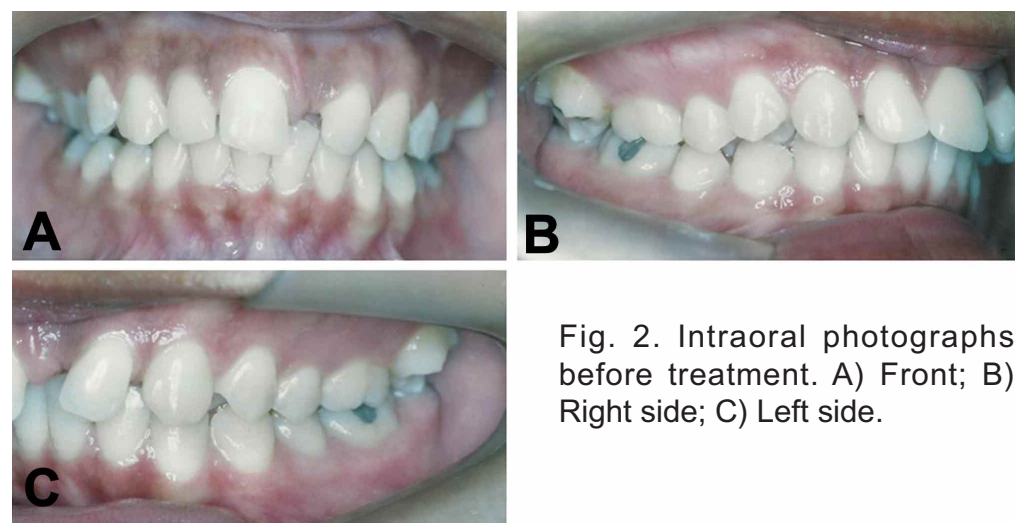

Fig. 2. Intraoral photographs before treatment. A) Front; B) Right side; C) Left side.
Table I. Baseline and post-treatment measurements obtained in the cephalometric analysis

\begin{tabular}{lccc}
\hline Factor & Clinical norm & Before treatment & After treatment \\
\hline NAP & $0^{\circ}$ & $20^{\circ}$ & $16^{\circ}$ \\
SNA & $82^{\circ}$ & $95.1^{\circ}$ & $89^{\circ}$ \\
SNB & $80^{\circ}$ & $84^{\circ}$ & $81^{\circ}$ \\
ANB & $2^{\circ}$ & $11^{\circ}$ & $9^{\circ}$ \\
SDN & $76^{\circ}$ & $80.7^{\circ}$ & $78^{\circ}$ \\
SN.GoGn & $32^{\circ}$ & $23.2^{\circ}$ & $27^{\circ}$ \\
SN.Gn & $67^{\circ}$ & $62.3^{\circ}$ & $66^{\circ}$ \\
1.1 & $131^{\circ}$ & $123.7^{\circ}$ & $128^{\circ}$ \\
1.NA & $22^{\circ}$ & $14.1^{\circ}$ & $7^{\circ}$ \\
1-NA & $4 \mathrm{~mm}$ & $2.6 \mathrm{~mm}$ & $1 \mathrm{~mm}$ \\
1.NB & $25^{\circ}$ & $31.2^{\circ}$ & $36^{\circ}$ \\
1-NB & $4 \mathrm{~mm}$ & $7.4 \mathrm{~mm}$ & $6 \mathrm{~mm}$ \\
1-Line I & 0 & $-2.2 \mathrm{~mm}$ & $-1 \mathrm{~mm}$ \\
HNB & $9^{\circ}$ to $2^{\circ}$ & $21.5^{\circ}$ & $16^{\circ}$ \\
H-nose & $9-11 \mathrm{~mm}$ & $-3.1 \mathrm{~mm}$ & $2 \mathrm{~mm}$ \\
FMA & $25^{\circ}$ & $21.8^{\circ}$ & $26^{\circ}$ \\
FMIA & $68^{\circ}$ & $54.3^{\circ}$ & $49^{\circ}$ \\
IMPA & $87^{\circ}$ & $103.9^{\circ}$ & $106^{\circ}$ \\
\hline
\end{tabular}

The radiographic examinations showed that tooth \#21 was unerupted and poorly positioned in the buccal and horizontal directions at the height of the anterior nasal spine. The upper and lower third molars were also poorly positioned and impacted. No other abnormality was verified (Fig. 4).

\section{Treatment Goals}

- Creating a relationship of the maxillary tooth occluding between two lower teeth;

- Reducing biprotrusion, thus providing a harmonious profile;

- Reducing overjet, closing the diastema caused by impaction of tooth \#21, and obtaining laterality and protrusion functions.

Treatment Alternatives. Some alternatives for the treatment of this malocclusion are described below:

- Orthodontic traction of the maxillary left central incisor (\#21) followed by the extraction of maxillary first premolars;

- Extraction of the two maxillary first premolars (\#14 and \#24) and the impacted 

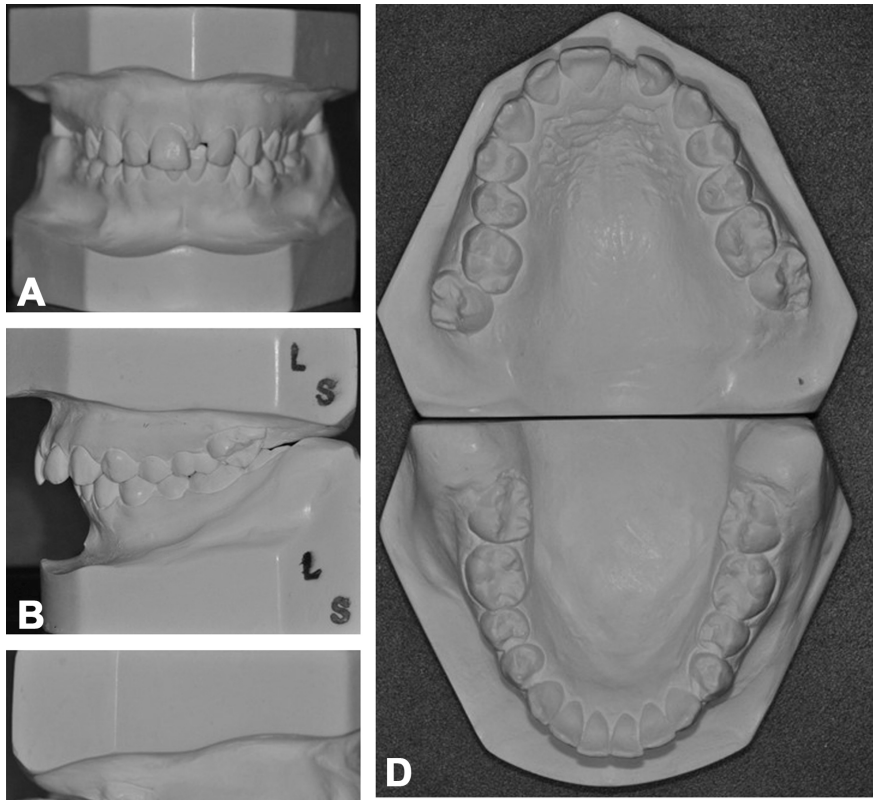

Fig. 3. Photographs of plaster casts before treatment. incisor (\#21) with subsequent installation of an osseointegrated implant in the region of dental element \#21;

- Extraction of the maxillary right first premolar (\#14) and the maxillary left central incisor (\#21), followed by mesialization of the left lateral incisor (\#22) and its reanatomization into the central incisor;
- Extraction of both maxillary central incisors followed by diastema closure and re-anatomization steps (lateral incisors turning into central incisors and canines turning into lateral incisors). This was the selected option reported herein.

Treatment Progress. The treatment selected was the extraction of the right and left maxillary central incisors, followed by mesialization and reanatomization of maxillary lateral incisors, canines, and premolars into central incisors, lateral incisors, and canines, respectively, leading the molars to Angle Class II relationship.

Initially, the extraction of tooth \#21 (unerupted) was requested so the treatment could be started. The orthodontic treatment began by cementing the transpalatal bar between teeth \#16 and \#26 in order to anchor the verticalization of teeth \#17 and \#27. Subsequently, a fixed appliance was installed - Roth prescription (Abzil, São José do Rio Preto, SP, Brazil), 0.022"X0.028" slot.

Then, the extraction of the maxillary right incisor (\#11) was requested, considering its crown was worn and used as a temporary crown. The initial wires used were 0.014 " and $0.016 " \mathrm{NiTi}$. Later, the thermoactivated rectangular $0.017 " \mathrm{~N} 0.025$ " wires were used and the mesialization of the left and right lateral incisors was performed, always along with interproximal wear on the extracted central incisor.

As the edentulous space was reduced, the re-anatomization of the maxillary anterior teeth (\#12
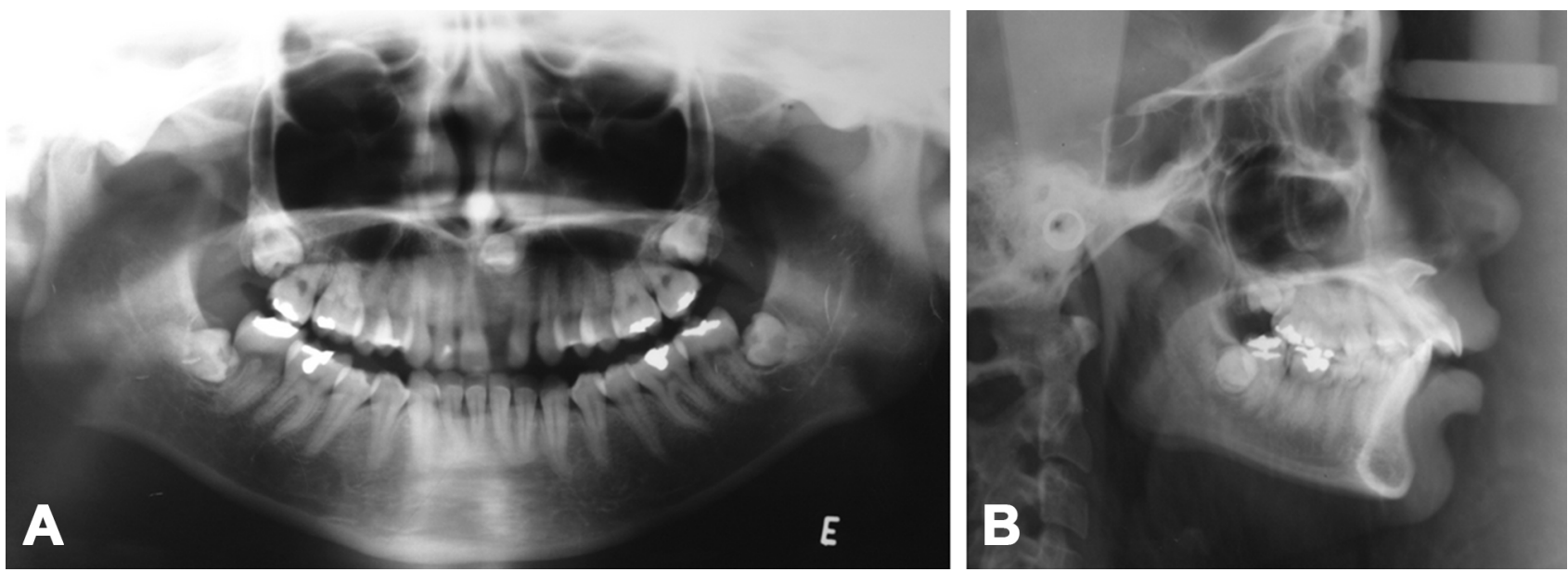

Fig. 4. Panoramic radiograph before treatment showing an unsatisfactory position of tooth 21 . The lateral teleradiography elucidates the position of tooth 21 . 
and \#22) was performed. The brackets were rebonded to such teeth before the mesialization movement of all anterior maxillary teeth. The $0.019 " \times 0.025 "$ steel wire was used to start the mesialization movements of maxillary canines and premolars, aided by intermaxillary $1 / 8$ elastics with Class III vector. After mesialization, the re-anatomization of maxillary canines and premolars was performed.

A slice was made in the mandibular teeth \#3343 for better placing the incisors relative to the symphysis, considering the lower incisors were buccally oriented as shown in the IMPA measurement of $103.9^{\circ}$, 1. NB of $31.2^{\circ}$, and $1 / . / 1$ of $123.7^{\circ}$ (Table I).
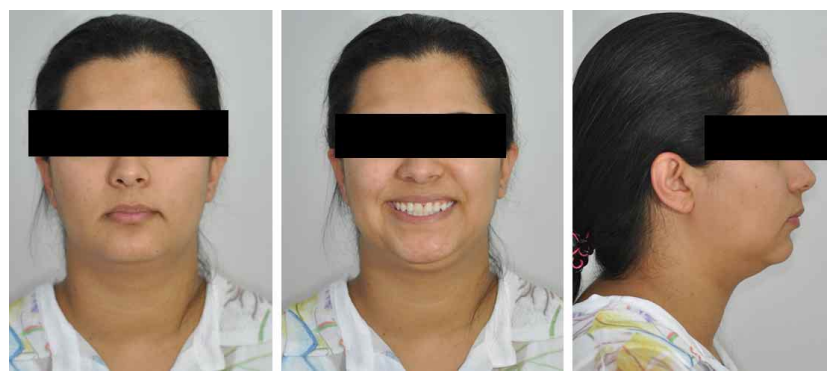

Fig. 5. Extraoral photographs after treatment. A) Front; B) Smiling; C) Profile.

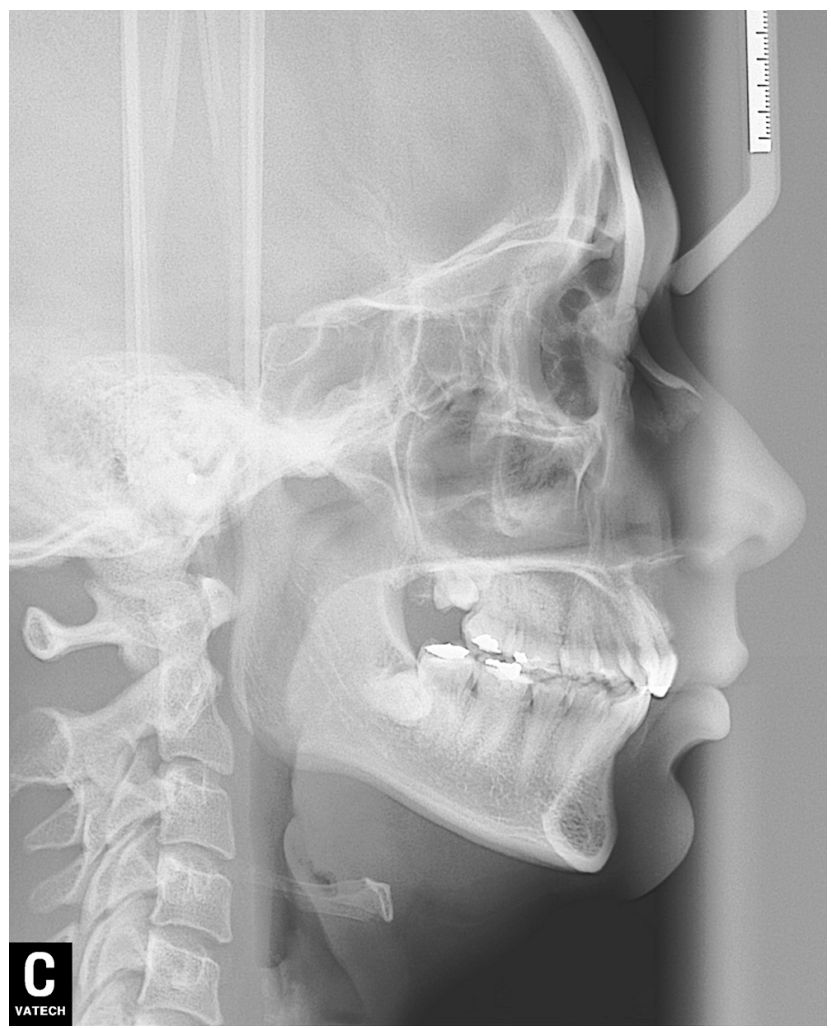

Fig. 6. Lateral teleradiography after treatment. Note the position of point $A$.
Two years after the beginning of treatment, the intercuspation procedure was started. At the end of intercuspation and occlusal adjustment, the fixed appliance was removed and the retainers were installed. A fixed hygienic retention for maxillary teeth \#13-23 was installed in association with a removable retention for the mandibular arch (Wraparound), for an intended use of 24 months.

Treatment Results. The following results were achieved: relationship of an upper tooth occluding between two lower teeth, reduction of biprotrusion and overjet, closure of maxillary anterior diastemas (Figs. 5 and 6), functional activity with contact between incisors in protrusive movements, and group function in lateral movements without contact with the unworked side. The radiographic follow-up showed no significant absorption in the roots of the teeth due to orthodontic movements. The cephalometric Point A was found to be positioned posteriorly, leading to profile improvements (Fig. 7).
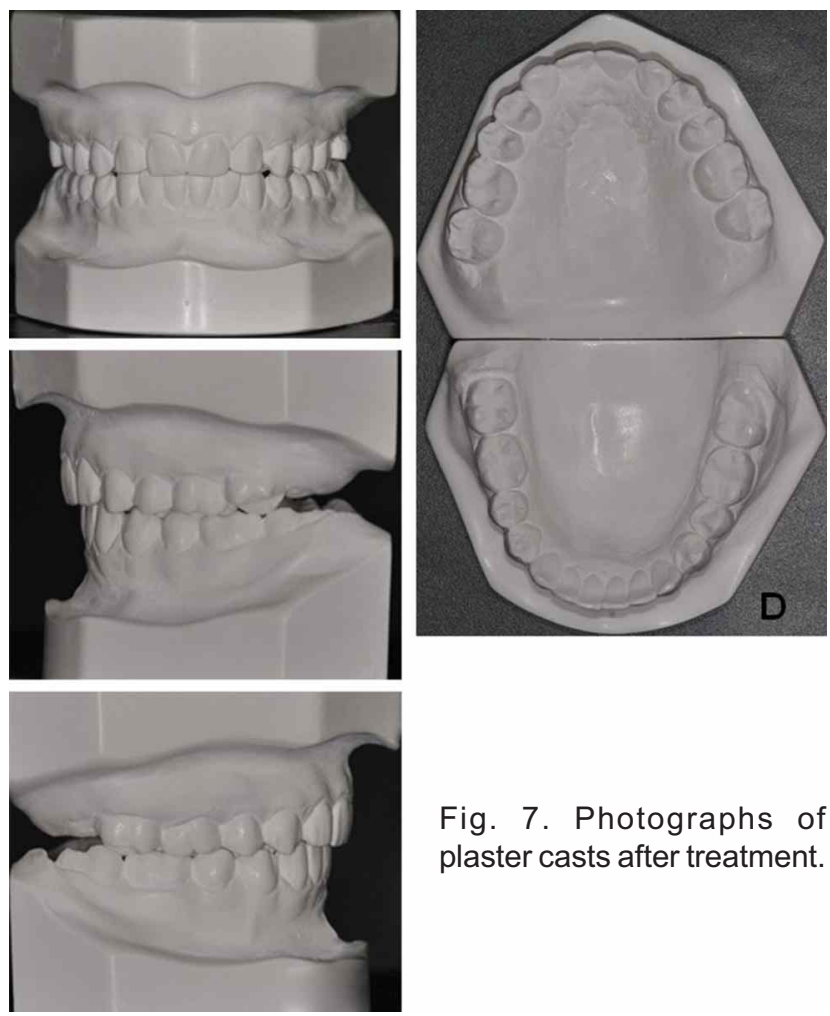

Fig. 7. Photographs of plaster casts after treatment.

Finally, Figure 7 shows a harmonious gingival contour that contributes to acceptable gingival aesthetics. The lower incisors underwent lingual inclination, which improved their relationship with the middle of the symphysis. 

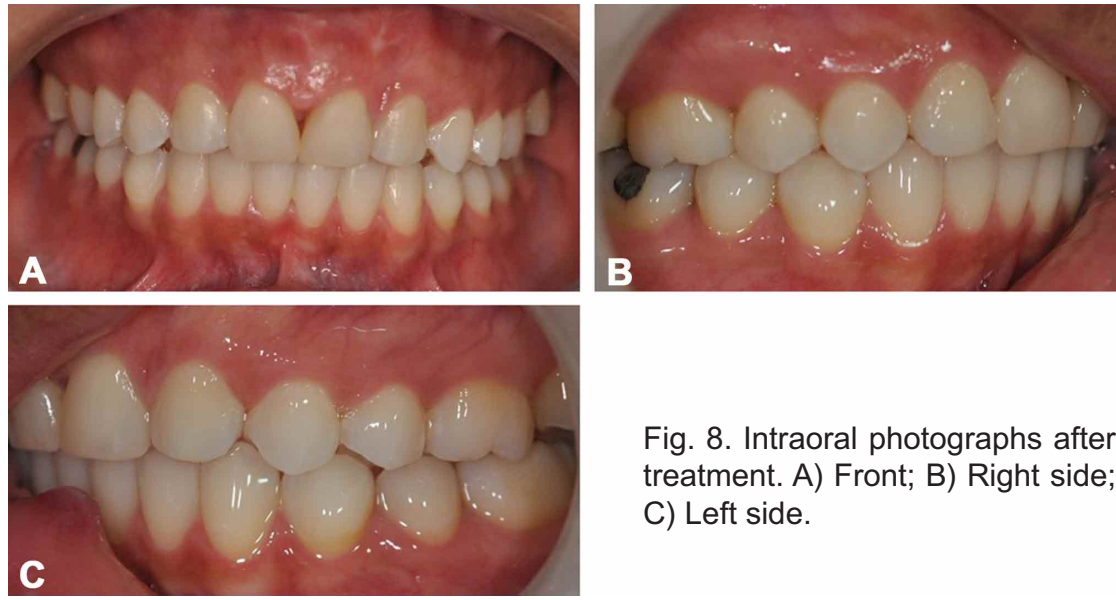

Fig. 8. Intraoral photographs after treatment. A) Front; B) Right side; C) Left side.
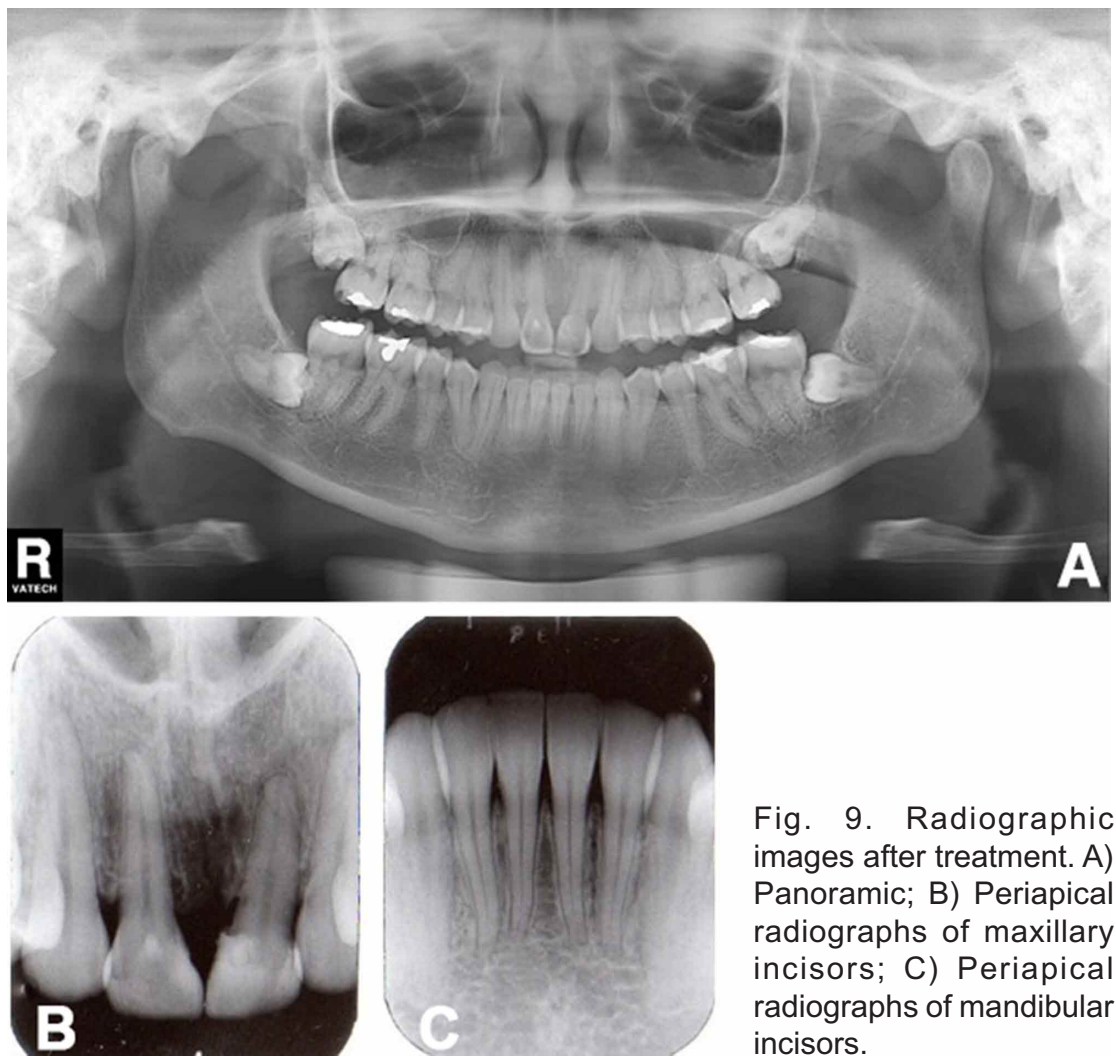

Fig. 9. Radiographic images after treatment. A) Panoramic; B) Periapical radiographs of maxillary incisors; C) Periapical radiographs of mandibular incisors.

\section{DISCUSSION}

Dental eruption is a physiological process that should be impeccably precise. The deciduous and permanent teeth are formed within the alveolar bone and they erupt in a sequence established by nature (Neto \& Falcão, 2014). Failures in tooth eruption may be caused by certain conditions such as trauma, lack of arch space, ankylosis of deciduous teeth, or the existence of physical barriers such as supernumerary teeth, tumors, or

cysts (Romero-Maroto \& SáezGómez, 2009). In this case report, the patient presented the left maxillary central incisor (\#21) with dilacerated root and crown in horizontal position, which prevented traction.

The extraction of premolars is widely accepted by orthodontists in the treatment of Angle Class II malocclusion, for it allows obtaining a satisfactory occlusal and aesthetic outcome (Zentner et al., 2003; Janson et al., 2007).

In this report, maxillary protrusion might be compensated by extracting maxillary premolars and the left central incisor, replacing the latter with an osseointegrated implant and fixed prosthesis with an artificial tooth. However, the patient declined this option due to the number of dental extractions and the financial cost. Another option proposed and accepted by the patient was the extraction of the right and left maxillary incisors, followed by the re-anatomization of lateral incisors into central incisors, canines into lateral incisors, and premolars into canines. The main advantages of this approach are preventing osseointegrated implant installation, preserving two natural teeth in the maxillary arch (upper first premolars), and reducing the time and total cost of orthodontic treatment. Reducing treatment time is one of the approaches for preventing the occurrence of external root resorption, which is a major sequel from orthodontic movement in association with other factors.

In addition to cost, another disadvantage of the treatment with osseointegrated implants is that the patient of the present study was a young adult, which means lack of growth in the implant installation 
area. Moreover, growth and dental extrusion are present in all three dimensions of other adjacent regions and according to some studies, these would likely occur in the third and fourth decades of life, causing a future demand for replacing the osseointegrated implant (Iseri \& Solow, 1996). Another difficulty would lie in controlling the gingival contour in the implant region without the existence of shadows, as this is an aesthetically demanding area (Janson et al., 2010). In this case, the option of extracting the maxillary central incisors was a treatment alternative for Class II malocclusion, because the inappropriate position of tooth \#21 did not allow its traction. Preserving the natural tooth and migrating it into the extraction space help correcting bone defects, because when the tooth is replaced slowly, the periodontal support structures follow the movement and form the alveolar bone in the extraction space (Robertsson \& Mohlin, 2000; Deryckere et al., 2001).

In order to achieve a satisfactory functional and aesthetic result, several issues had to be resolved. The maxillary lateral incisors had thin roots, which implicated in more cautious and limited movements to prevent the inclination of roots during displacement; otherwise, re-anatomization would be challenging and there would be loss of interdental papilla, and consequently the formation of black triangles.

This situation was managed with the use of bends in the finishing arch or angulations in the brackets, in order to create root parallelism. However, the patient decided to have the appliance removed before the end of treatment, when the crown was still inclined, making it difficult to reshape the maxillary lateral incisor, thus highlighting the black triangle due to the lack of interdental papilla (Figs. 8 and 9). A papillary reconstruction was performed by means of an envelope flap and a graft of attached gingiva in the region between the maxillary lateral incisors, after root parallelism. This procedure was refused by the patient.

The extrusion of maxillary canines and the intrusion of maxillary premolars would be performed for a correct gingival height, but the treatment ended early. The appropriate aesthetic treatment should include tooth whitening, porcelain veneers, and gingival plastic surgery (Ishihara et al., 2013), but the result obtained was pleasingly accepted by the patient.

Space closure through maxillary canines replacing the lateral incisors provides a satisfactory result, but leads to major occlusal changes (Ishihara et al.). The maxillary canine is larger in the buccal- palatal direction than the maxillary incisor. Therefore, wearing the palatal surface is required to avoid premature contacts with the mandibular incisors (Janson et al., 2010). In addition, the labial surface should be worn to become flatter. Studies have shown that wearing the palatal and labial surfaces does not damage either dentin or pulp (Janson et al. 2010; Ishihara et al.). Thus, the cusp tip and the labial surface were reduced to form a flat surface. The angles were rounded in the mesial and distal aspects to complete the re-anatomization of maxillary canines.

Canines are responsible for disocclusion during right and left lateral movements. In the present case, this function was not performed due to the mesialization towards the region of the maxillary incisor. Thus, disocclusion was adjusted to be performed by a group of teeth, which is also considered satisfactory. In parallel, individual torques, extrusions, and dental rotations were performed to ensure proper mandible lateralization movements. A radiographic follow-up should be conducted, as a long-term problem may occur, meaning the root volume of the premolar is smaller than that of the maxillary canine (Ishihara et al.).

This type of mechanics is a potential therapeutic option, considering the biological limits and periodontal structures. The treatment plan focused on the impossibility of traction of the maxillary central incisor, which was then replaced by adjacent teeth occupying the gap left by the extractions. This procedure was chosen because the patient refused to have an osseointegrated implant and fixed prosthesis with an artificial tooth.

All treatment goals were satisfactorily achieved and the patient accepted the final result.

\section{CONCLUSION}

The atypical extraction of a maxillary central incisor is not a routine protocol in orthodontics. However, in the case of poorly positioned teeth that complicate and/or prevent traction, atypical extraction might be a good alternative to preserve the natural teeth and prevent the need for an osseointegrated implant in adult/young patients.

The re-anatomization of maxillary anterior teeth and gingival plastic surgery are required for a satisfactory aesthetic result. 
LIMA, A. P. B.; CERICATO, G. O.; PITHON, M. M.; FRANCO, A.; HERVAL, A. M. \& PARANHOS, L. R. Extracción atípica de incisivo central maxilar en la corrección de la maloclusión de Angle Clase II. Int. J. Odontostomat., 13(3):292-298, 2019

RESUMEN: Este caso clínico describe el tratamiento de la mala oclusión de Clase II en un paciente con ausencia de uno de los incisivos centrales superiores debido a impactación. El abordaje del tratamiento consistió en la extracción de este elemento dental y del otro incisivo central, seguido del cierre de los diastemas y reanatomización de los incisivos laterales en incisivos centrales. Los resultados obtenidos fueron considerados satisfactorios con relación a los aspectos oclusales, estéticos y funcionales. Así, esta planificación se puede utilizar como una nueva alternativa de abordaje terapéutico para estos casos.

PALABRAS CLAVE: movimiento dentario, extracción dentaria, maloclusión de Angle clase II, ortodoncia correctiva.

\section{REFERENCES}

Deryckere, F.; Neyt, L.; Abeloos, J.; De Clercq, C.; Mommaerts, M. \& De Mot, B. Treatment of a congenitally missing upper lateral incisor with an implant. Rev. Belge. Med. Dent. (1984), 56(1):30-4, 2001.

El Refaei, A. K.; Fayed, M. M.; Heider, A. M. \& Mostafa, Y. A. Treatment of a complex malocclusion in a growing skeletal Class II patient. J. Clin. Orthod., 48(3):181-9, 2014.

Hematpour, S.; Rahimi, H. \& Mahmoudi, F. Treatment of a unilateral class II malocclusion with Sabbagh Universal Spring: a case report. Int. J. Orthod. Milwaukee, 25(2):9-12, 2014.

Iseri, H. \& Solow, B. Continued eruption of maxillary incisors and first molars in girls from 9 to 25 years, studied by the implant method. Eur. J. Orthod., 18(3):245-56, 1996.

Ishihara, Y.; Kuroda, S.; Sumiyoshi, K.; Takano-Yamamoto, T. \& Yamashiro, T. Extraction of the lateral incisors to treat maxillary protrusion: quantitative evaluation of the stomatognathic functions. Angle Orthod., 83(2):341-54, 2013.

Janson, G.; Barros, S. E.; de Freitas, M. R.; Henriques, J. F. \& Pinzan, A. Class II treatment efficiency in maxillary premolar extraction and nonextraction protocols. Am. J. Orthod. Dentofacial Orthop., 132(4):490-8, 2007.

Janson, G.; Valarelli, D. P.; Valarelli, F. P.; de Freitas, M. R. \& Pinzan, A. Atypical extraction of maxillary central incisors. Am. J. Orthod. Dentofacial Orthop., 138(4):510-7, 2010.

Livas, C.; Halazonetis, D. J.; Booij, J. W. \& Katsaros, C. Extraction of maxillary first molars improves second and third molar inclinations in Class II Division 1 malocclusion. Am. J. Orthod. Dentofacial Orthop., 140(3):377-82, 2011.

Nagayama, K.; Tomonari, H.; Kitashima, F. \& Miyawaki, S. Extraction treatment of a class II division 2 malocclusion with mandibular posterior discrepancy and changes in stomatognathic function. Angle Orthod., 85(2):314-21, 2015.

Neto, P. G. \& Falcão, M. C. Eruption chronology of the first deciduous teeth in children born prematurely with birth weight less than 1500 g. Rev. Paul. Pediatr., 32(1):17-23, 2014.
Pithon, M. M. Treatment of class II malocclusion with open bite and absence of central maxillary incisor lost by trauma aided by use oforthodontic mini-implants. Dent. Traumatol., 30(1):65-70, 2014.

Robertsson, S. \& Mohlin, B. The congenitally missing upper lateral incisor. A retrospective study of orthodontic space closure versus restorative treatment. Eur. J. Orthod., 22(6):697-710, 2000

Romero-Maroto, M. \& Sáez-Gómez, J. M. Eruption of primary dentition--a grave health problem according to Spanish doctors of the XVI-XVIII centuries. J. Dent. Res., 88(9):77780, 2009.

Sabri, R. Treatment of a Class I crowded malocclusion with an ankylosed maxillary central incisor. Am. J. Orthod. Dentofacial Orthop., 122(5):557-65, 2002.

Saikoski, L. Z.; Cançado, R. H.; Valarelli, F. P. \& de Freitas, K. M. Dentoskeletal effects of Class II malocclusion treatment with the Twin Block appliance in a Brazilian sample: a prospective study. Dental Press J. Orthod., 19(1):36-45, 2014.

Verma, S. K.; Chauhan, A.; Rastogi, K. \& Bhushan, R. Correction of class II division I malocclusion after extraction using Roth prescription. B. M. J. Case Rep., 2013:bcr2013009766, 2013.

Zentner, A.; Peylo, S. \& Brothag, D. Predictive value of morphologic parameters for successful correction of Class II Division 2 malocclusion. Am. J. Orthod. Dentofacial Orthop., 123(3):279-85, 2003.

Corresponding author:

Professor Luiz Renato Paranhos

Av. Pará, 1720, Bloco 2G, sala 1

Umuarama

CEP: 38405-320. Uberlândia-MG

BRASIL

E-mail: paranhos.Irp@gmail.com

Received: 26-10-2018

Accepted: 12-04-2019 